\title{
Welcome to the first issue of Public Health Research \& Practice
}

\section{Sally Redmanª and Sarah Thackway ${ }^{b}$}

a Sax Institute, Sydney, NSW, Australia

b NSW Ministry of Health, Sydney, Australia

\section{Article history}

Publication date: November 2014

Citation: Redman S, Thackway S. Welcome to the first issue of Public Health Research \& Practice. Public Health Res Pract. 2014;25(1):e2511400. doi: http://dx.doi. org/10.17061/phrp2511400

\section{Welcome}

Welcome to the first issue of Public Health Research \& Practice, formerly the NSW Public Health Bulletin. We hope this journal - which remains peer reviewed and listed on the prestigious MEDLINE database - will bring together the best of research, policy and practice. Much of the focus of the former Bulletin remains, but you will notice some new or strengthened directions. We have a special 'In Practice' section dedicated to case studies and experience from the field of public health, and we intend the journal to be a forum for discussion about new and better methodologies in policy-relevant public health research.

Public Health Research \& Practice will publish quarterly online and will build on the rich tradition of the former Bulletin. We will publish articles that are relevant to policy and practice, including original research and reviews, articles that improve or illuminate methods of research, and overviews of emerging or debated issues. We will also publish examples of innovative programs or policies, new data or perspectives from the field, and brief reports of special relevance to strengthening public health practice.

This issue has a focus on systems approaches to the prevention of chronic disease. As outlined in the paper by Wilson and colleagues, chronic disease is the major cause of premature death in Australia. There is growing recognition that preventing chronic disease will require multilevel, multisector approaches, and that systems thinking can make a unique contribution to establishing more effective approaches to prevention.

In light of this, the establishment of an NHMRC Partnership Centre to address systems approaches to the prevention of chronic disease is very timely. The Australian Prevention Partnership Centre is funded by the NHMRC, the Australian Government Department of Health, NSW Ministry of Health, ACT Health and the HCF Research Foundation, and is directed by Professor Andrew Wilson. Wilson and colleagues provide an overview of the Prevention Centre, highlighting its systematic approach to improving knowledge, synthesis, communication, capacity development and implementation in chronic disease prevention (www.phrp.com.au/issues/vol112014/australianprevention-partnership-centre-systems-thinking-prevent-lifestyle-relatedchronic-illness).

Giles-Corti and colleagues describe a number of significant projects to be undertaken as part of the work of the Prevention Centre to develop 
and validate a national set of environmental liveability indicators relating to chronic disease. This is an example of an approach to building the infrastructure for a prevention system (www.phrp.com.au/issues/ vol112014/reconnecting-urban-planning-health-protocoldevelopment-validation-national-liveability-indicatorsassociated-noncommunicable-disease-risk-behaviourshealth-outcomes); over time, it will enable us to monitor whether we are creating environments that better support the prevention of chronic disease. Continuing this theme, Bauman and Nutbeam describe some challenges in evaluating the impact of complex intervention programs that arise from multilevel and multisectoral thinking. To underpin the measurement and monitoring of populationwide prevention programs, they propose a framework designed to provide meaningful evidence about their impact on chronic disease (www.phrp.com.au/issues/ vol112014/planning-evaluating-population-interventionsreduce-noncommunicable-disease-risk-reconcilingcomplexity-scientific-rigour).

In their 'Research methods' paper, Siokou, Morgan and Shiell describe an emerging method to help understand systems concepts and support systems practice. Group model building is a way of engaging stakeholders in the development of causal loop diagrams and other system dynamics models. The process is designed to engage policy makers and practitioners in thinking about issues that have multiple interconnected causes, and involve multiple agencies and organisations with different agendas (www.phrp.com.au/issues/ vol2512014/group-model-building-participatoryapproach-understanding-acting-systems).

The 'In Practice' section includes an interesting paper by Farrell and colleagues that describes the experience of introducing a scaled-up capacity-building model designed to increase healthy eating and physical activity among children. This program included an innovative approach to monitoring the scaling up of program implementation at the state-wide level, which, as the authors note, may well have the potential for application to other policy areas (www.phrp.com.au/issues/vol2512014/ applying-performance-monitoring-framework-increasereach-adoption-childrens-healthy-eating-physical-activityprograms).

In this first issue of the renamed journal, we would particularly like to thank our hard-working Editorial Board members, who have helped guide its development.

We invite you to submit manuscripts (www.phrp.com. au/for-authors/submit-paper), make suggestions about themes or topics you would like to see covered in future issues (www.phrp.com.au/about-us/contact-us) and, of course, send us your feedback (www.phrp.com.au/aboutus/contact-us).

\section{Copyright: (c) (1) (2)}

(C) 2014 Redman and Thackway. This article is licensed under the Creative Commons Attribution-NonCommercial-ShareAlike 4.0 International License, which allows others to redistribute, adapt and share this work non-commercially provided they attribute the work and any adapted version of it is distributed under the same Creative Commons licence terms. See: http://creativecommons.org/licenses/by-nc-sa/4.0/ 